\title{
Energy Efficiency of Heating System Phased Introduction of Automatic Control Unit
}

\author{
Sergey A. Nazarychev ${ }^{1}$, Yuriy V. Vankov ${ }^{2}$, Julia N. Zvonareva $^{3}$, Yevgeniya V. Izmailova ${ }^{4}$ \\ ${ }^{1}$ Kazan Federal University, ${ }^{2,3,4}$ Kazan State Power Engineering University \\ Email: nazarichev.sa@gmail.com, Contact:89376185067
}

Received: 21st October 2017 Accepted: 16th November 2017, Published: 31st December 2017

\begin{abstract}
The introduction of automated accounting and control units (ACU) located directly in a heated building, in addition to comfortable conditions creation inside the premises, leads to the reduction of thermal energy consumption. The purpose of this paper is to evaluate the increase of a heat supply system energy efficiency with the introduction of automatic control units (ACU). The following experiments were carried out on a laboratory stand for the introduction of ACU: a building with an individual boiler room; a group of buildings located at equal distances from each other; a group of buildings at different distances from each other; the analysis of a heat network operation taking into account the introduction of automatic metering and control units. The research was carried out on the laboratory stand "Centralized heat supply" created from the components and the equipment of "Danfoss" company. The control of the stand operation is managed by a computer program written in the LabView environment. The obtained data were compared with the calculated ones and the economic effect on the introduction of equipment was estimated. The annual expected effect from the installation of metering units and automatic control can amount to $22 \%$ of the consumed thermal energy. In monetary terms, according to the tariff for heat energy in 2015, the reduction of heat consumption will allow homeowners to reduce the cost of services provided to the amount of about 347.52 thousand rubles per year (VAT included). In general, the effect of ACU project implementation is to reduce the heat consumption of the building considerably and, accordingly, to reduce the payment for consumed energy resources.
\end{abstract}

Keywords: Heat Supply, Heating System, Individual Heat Point, Automated Unit of Accounting and Regulation, Economic Efficiency.

\section{Introduction}

In Russian Federation the heat supply of large industrial enterprises and housing and communal services is carried out mainly centrally, which makes it possible to reduce the cost of heat production through the joint production of electricity and heat.

An important role in an effective functioning of centralized heat supply systems is played by the 2473 coordinated work of sources and consumers at the regulation of heat supply [1].

The main approach to thermal energy saving is the introduction of automatic control systems for heating, ventilation and hot water supply. According to the data of All-Russian Thermal Engineering Institute (Moscow), the installation of automatic control systems in individual heat points reduces heat consumption in the residential sector by $5-10 \%$, and by $40 \%$ in administrative premises.

The purpose of this paper is to evaluate the energy efficiency increase of the heat supply system with the introduction of automatic control units (ACU).

Objectives of the work:

1. To analyze the state of modern heat supply systems in RF.

2. To evaluate the feasibility of ACU introduction into an existing heat supply system.

3. To check the calculated data on the introduction of ACU at an experimental stand.

4. To estimate an economic effect of ACU introduction into a heat supply system.

\section{Methods \\ Heat Supply Systems}

In many regions of Russia, an "open" heat supply scheme operates, when the heating and ventilation systems of subscribers are connected by a a dependent scheme of connection to the heating networks, and a hot water supply system is connected in an open scheme.

Virtually all of subscriber heat points connected to district heating systems are equipped with an elevator heat input. The use of elevator units inhibits the introduction of energy-saving measures into heat supply systems, since it does not allow an automatic regulation of heat carrier parameters in a building providing comfortable conditions and an economical heat consumption [2].

All of the mentioned above led to the fact that, beginning from 2000, a large-scale transition from "open" dependent heat supply systems to "closed" independent systems with automated heat points began. However, the transition to modern heat supply systems with automated heat points put a number of problems before design, mounting, power supply organizations and heat consumers: 
1. The absence of a year-round circulation of a heat carrier in the main heat networks.

2. An outdated approach to design and installation of internal heat supply systems.

3. The need for modern heat supply system maintenance [3].

\section{Automatic regulation of Heat Consumption}

An automatic regulation of thermal energy consumption makes it possible to create a comfortable thermal regime in a building due to a more qualitative and precise regulation.

The basic principle of an automatic systems is to regulate a flow at a measured temperature. At the increase of an outside air temperature and an indoor temperature, a heat carrier flow rate automatically decreases proportionately and vice versa it increases with the decrease of the temperature inside the room and outside air temperature. By reducing the flow rate, the value of consumed thermal energy decreases [4].

\section{Test Unit Description}

The research was carried out on the laboratory stand "Centralized heat supply" created from the components and the equipment of the company "Danfoss" [5]. Figure 2 and 3 show the appearance of the stand and its scheme. The stand operation is managed by a computer program written in LabView environment.

The stand consists of two circuits of a heat supply system, each of which has two reduction electric drives AME 33, two control valves VM2, one differential pressure regulator AVP, and one manual balancing valve. There are three reduction electric drives on the mains network. The stand contains Grundfos pump, an expansion tank, a control unit and a frequency converter [6].

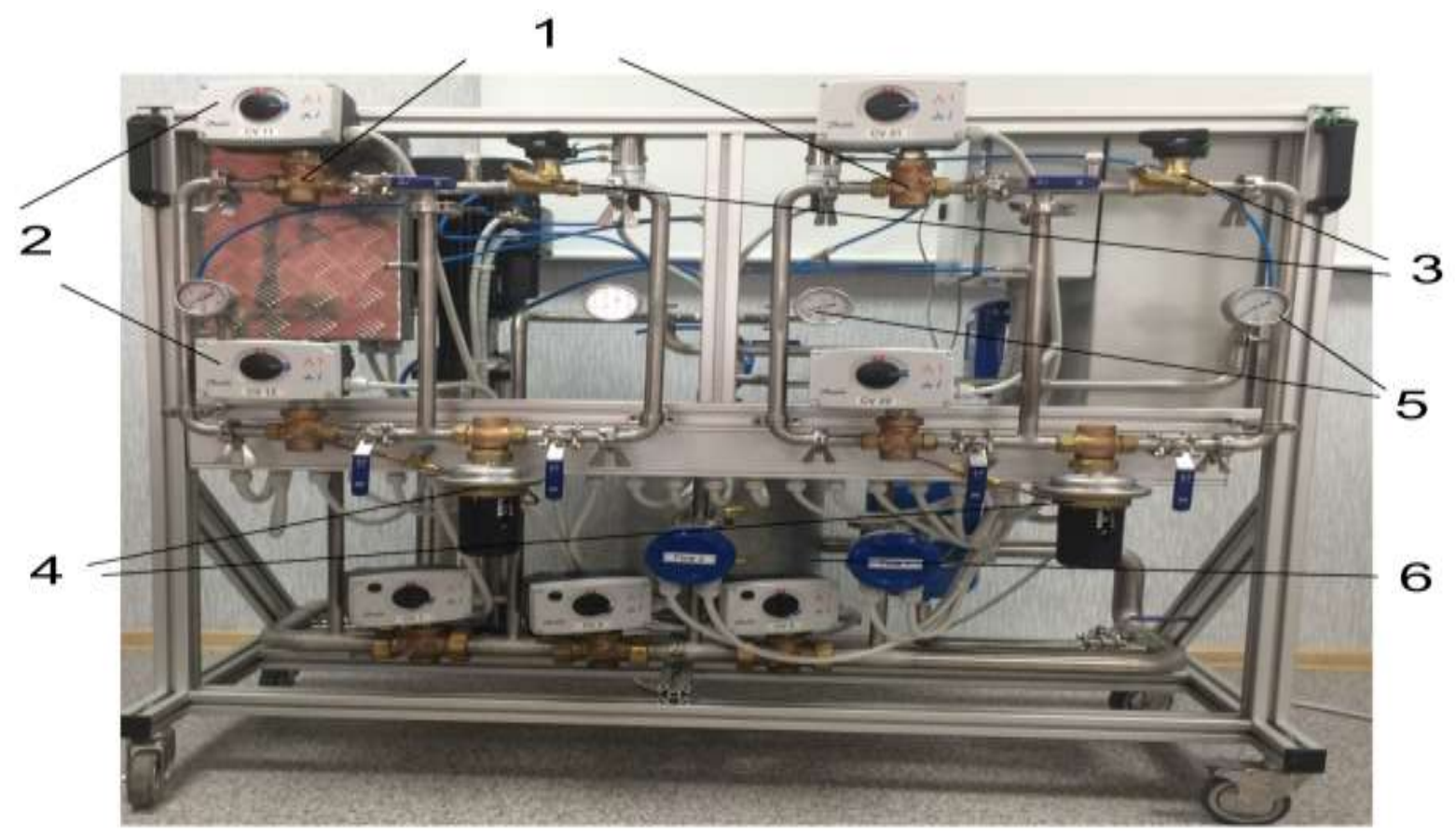

Fig. 2 Laboratory Stand "Centralized Heat Supply"

1 - Regulating Valve VM2, 2 - Reduction Electric Drive AME 33, 3 - Manual Balancing Valve, 4 - Differential Pressure Regulator AVP, 5 - Pressure Gauge, 6 - Expansion Tank. 


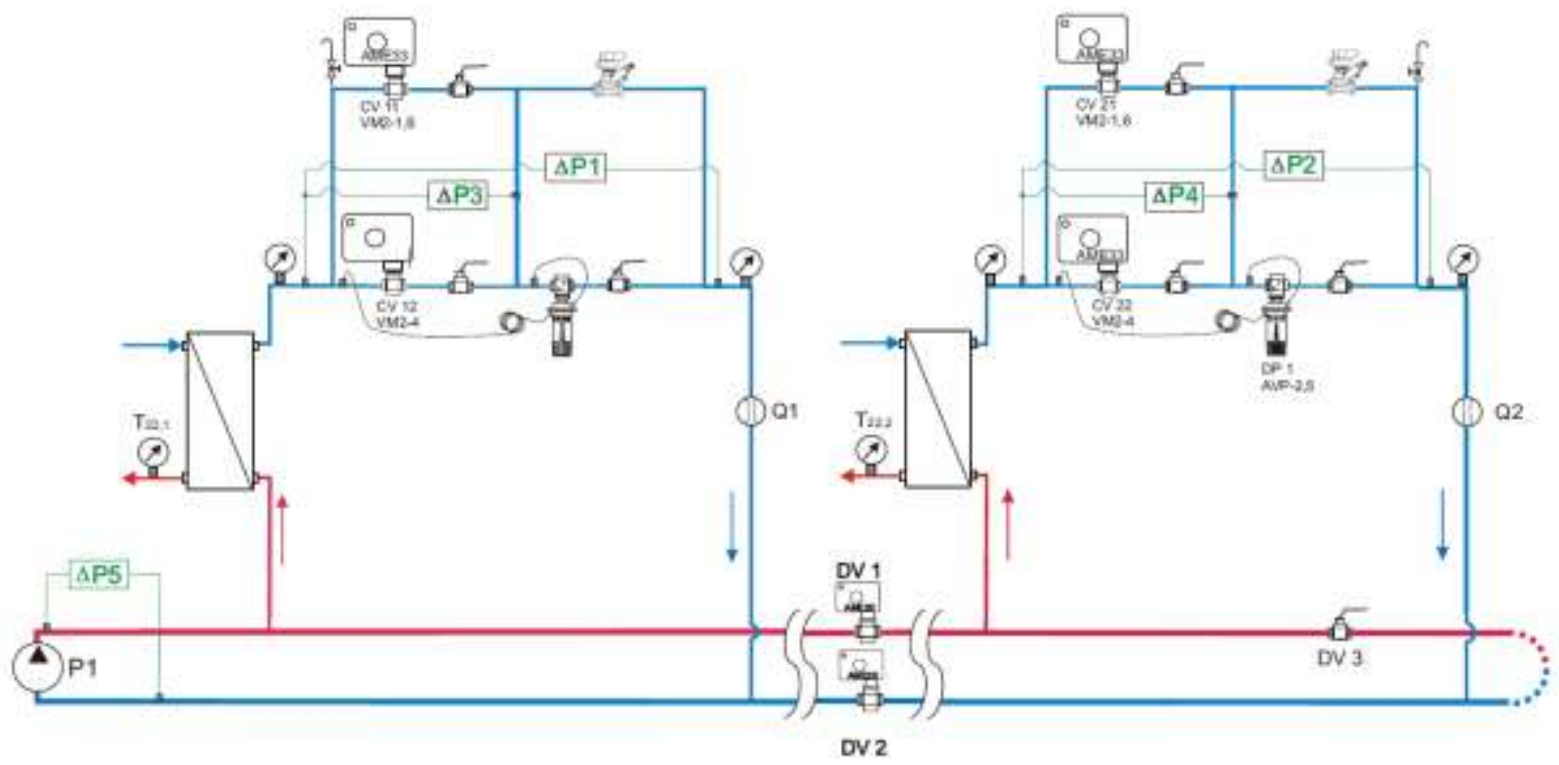

Fig. 3 Principal Stand Scheme

\section{Results}

\section{Building With a Separate Boiler Room}

In this operation mode, an assessment was made of automatic equipment influence on the operation of a heat supply system for a single consumer.

This experiment makes it possible to estimate the change in the flow rate of a heat carrier for a consumer equipped with a differential pressure regulator (DPR) and a control valve, with the fluctuations of a heat carrier flow in a heat network.

Figure 4 shows the change of a heat carrier flow rate at a start-up. The vibrations are associated with the operation of an automatic control valve. After the completion of transient processes, it outputs the flow to a given level and maintains it constant throughout a heating period.

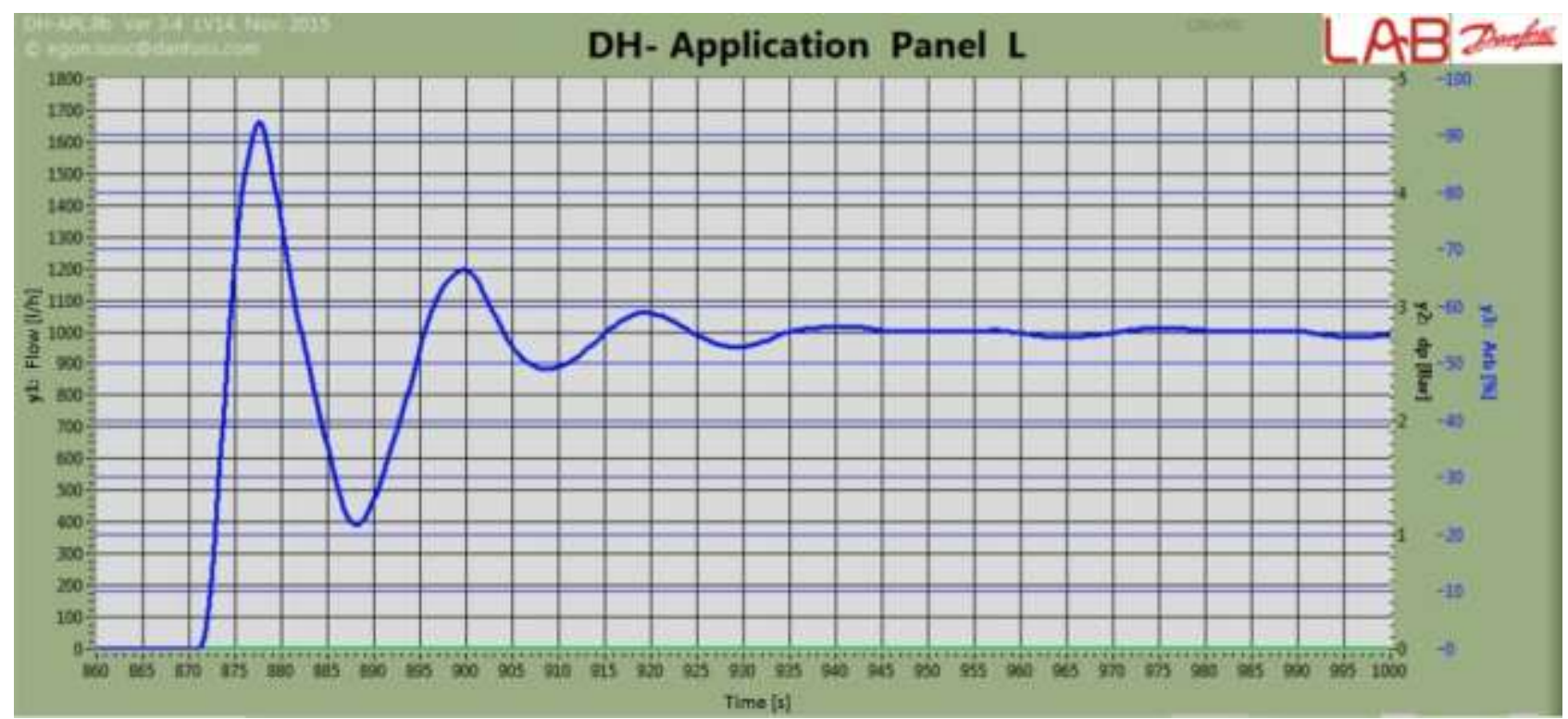

Fig. 4. Heat Carrier Flow Rate Change for a Single Consumer

The installation of a differential pressure regulator (DPR) and a control valve in a heating system allows to maintain a constant flow of a heat carrier for a consumer with the change of a heat carrier flow rate in a heating network. A constant flow of a heat carrier ensures a premise thermal comfort and saves up to $25 \%$ of the thermal energy by excluding overheating during autumn and spring periods.

Group of Buildings Located at Equal Distances from each other

The work of the stand in this mode makes it possible to estimate the change of a heat carrier flow rate for consumers not equipped with a DPR concerning the 
consumers equipped with automatic equipment. The graphs on Figure 5 show the change of the heat carrier flow rates for consumers equipped and unequipped with a differential pressure regulator. The consumption of the first consumer (blue line) with the installed DPR after the network flow increase has not grown significantly. At that, the second consumer (green line) without DPR has the increase of consumption by $20 \%$. Such a consumption increase leads to a significant increase of thermal energy consumption, and, accordingly, the payment for the supplied heat.

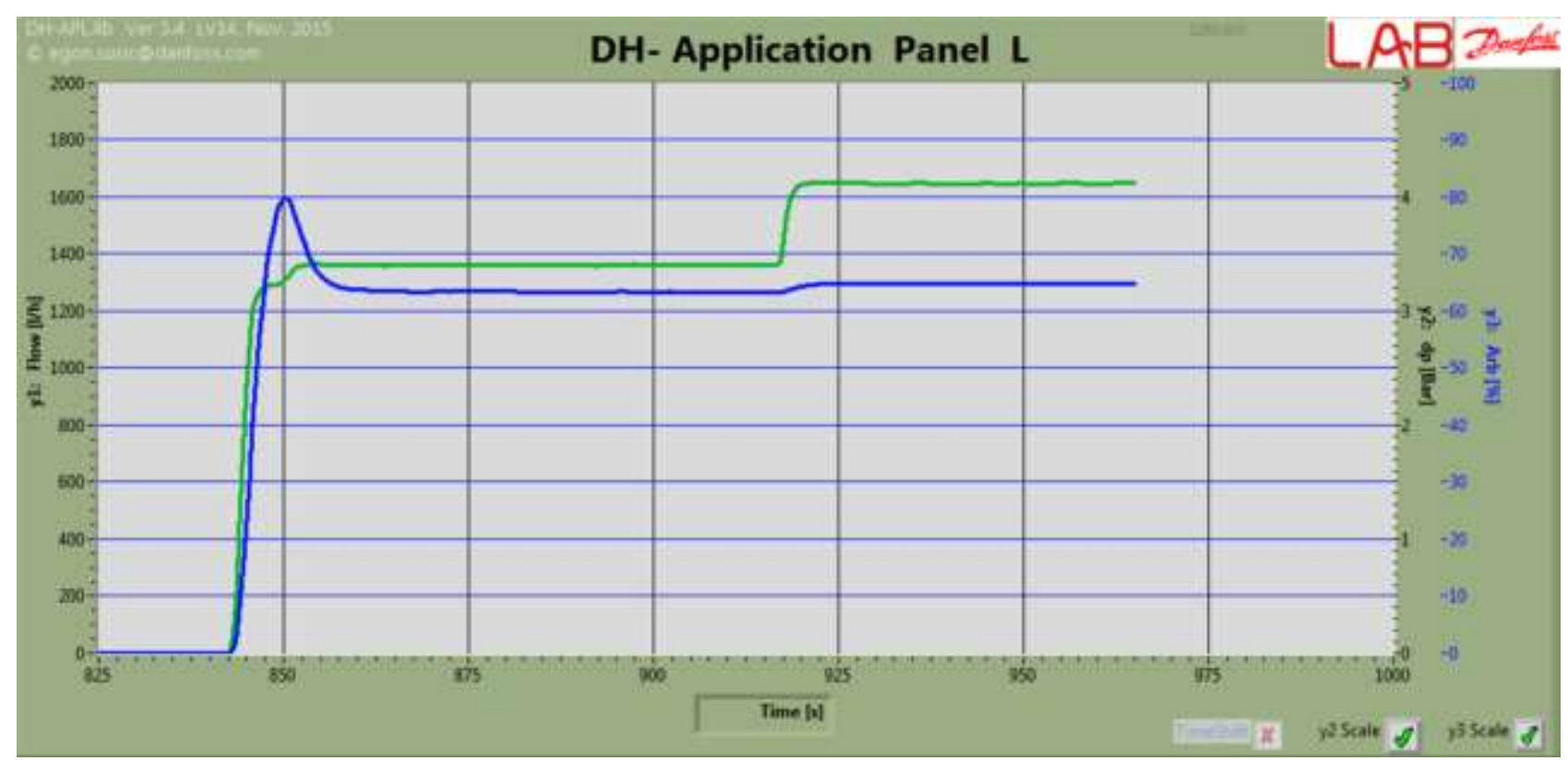

Fig.5 Changes of Heat Carrier Flow Rates for the Consumers Equipped with DPR (Blue Line) and without it (Green Line)

\section{Group of Buildings Located at Different Distances from each other}

This mode of the stand operation allows to estimate the mutual influence of heat supply systems for consumers on each other. The task of the experiment was to obtain an estimate of the effect of consumer automation unit operation equipped with a differential pressure regulator on a remote subscriber of the network not equipped with it. The results are shown on Figure 6.

The graphs show the changes of consumer consumption after the increase of the heat carrier flow rate in the network by $10 \%$. It can be seen that a remote consumer (green line) had the increase of the heat carrier flow rate, whereas the consumption remains at the calculated level for the first consumer. 


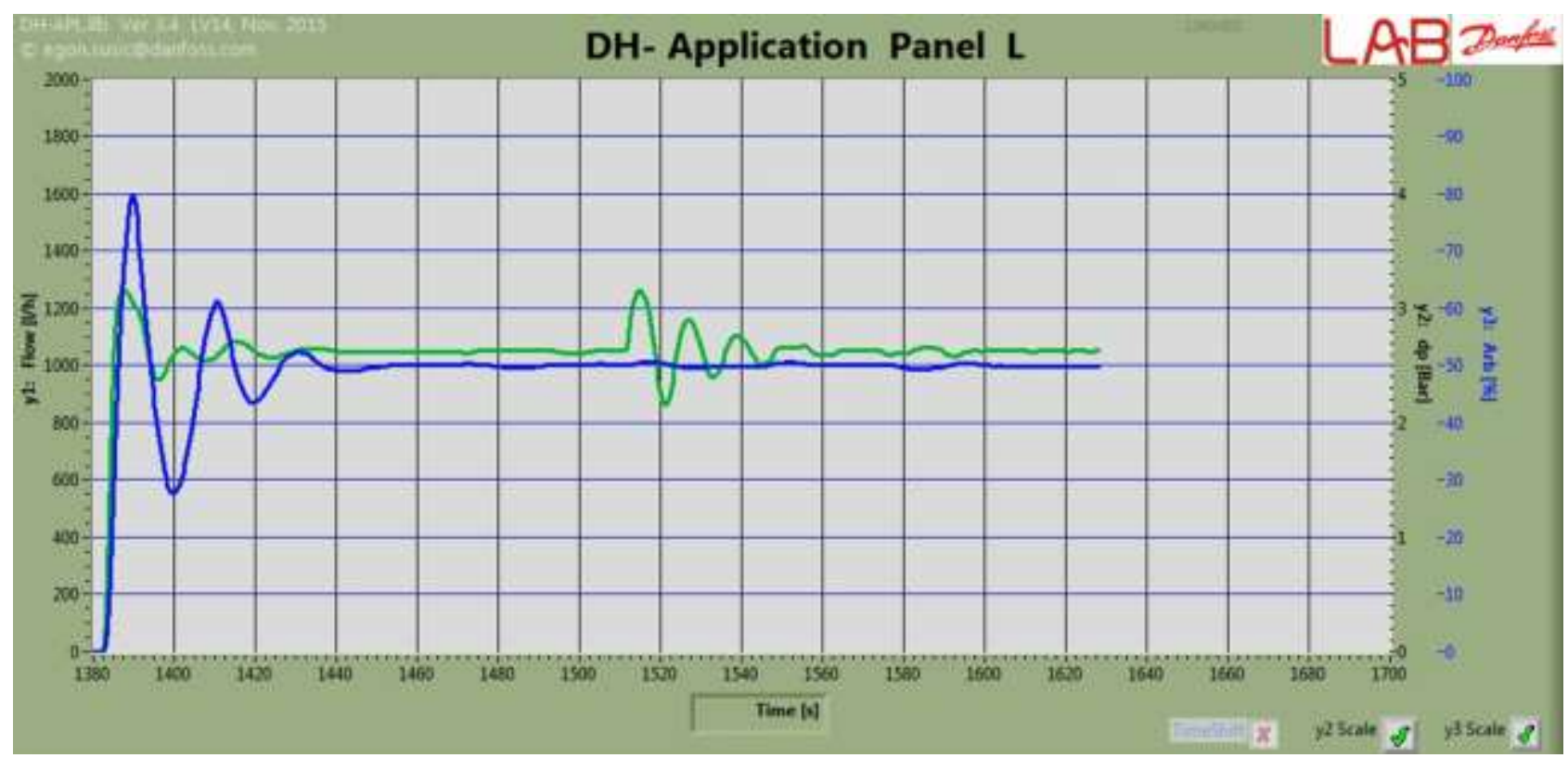

Fig.6. Change of the Heat Carrier Flow Rate from Two Subscribers. The Consumer with DPR (Blue Line), the Consumer without Automation (Green Line)

The graphs shown on Fig. 5,6 allow us to conclude that the installation of modern equipment for individual consumers of the existing heat supply system does not provide an energy-saving effect in the whole system.

\section{Analysis of Heat Network Operation taking into Account the Introduction of Automatic Metering and Control Units}

The initial data for the research was the performance of the heat supply system for the residential buildings in the 38th block of Kazan. The task of the experiment was to assess the impact of the phased introduction of ACU among the users of the existing heat network on the efficiency of heat supply for other consumers.
Each user set the actual flow of a heat carrier using the manual balancing valves, then ACU was turned on the first consumer ACU and the indicators of the first and second consumer were fixed. At that the pump simulating the source of heat supply worked for a constant maintenance of pressure. The experiment was conducted six times for each pair of consumers.

Figure 7 shows the graphs of the heat carrier flow rate change for the first pair of consumers. The blue line is the heat carrier flow rate for the first consumer, the green line indicates the heat carrier flow rate for the second consumer, the black line is the standard flow rate for the first consumer.

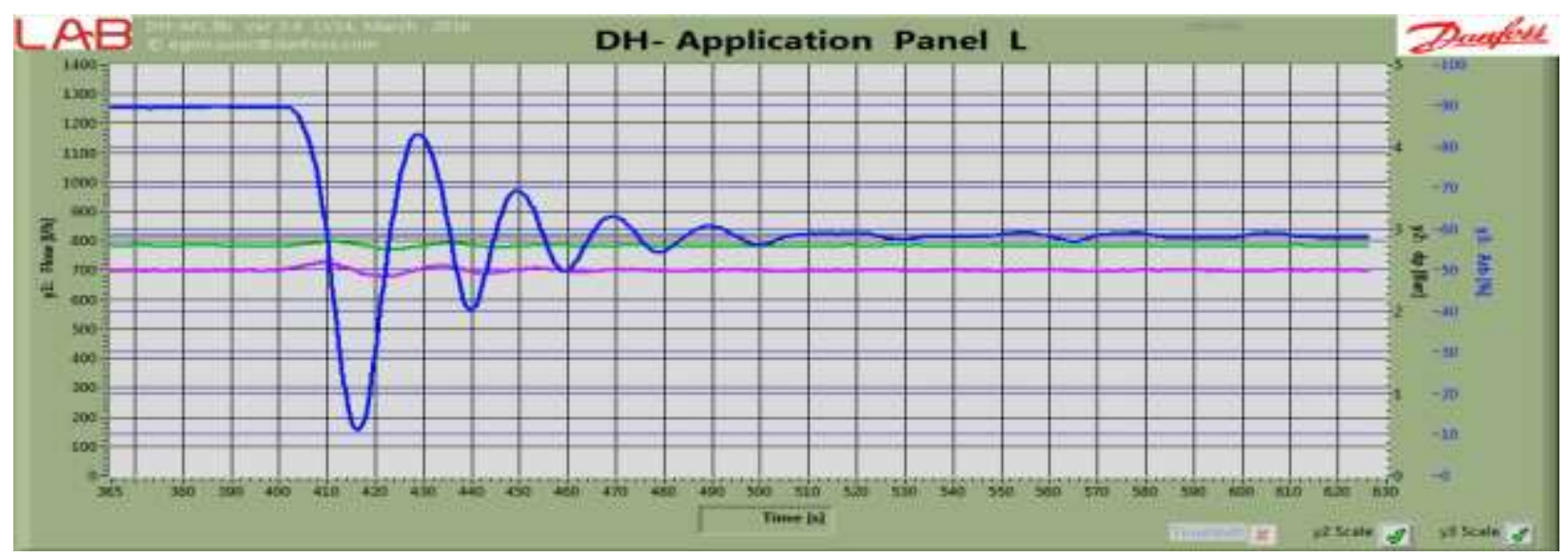

Fig.7 Change of the Heat Carrier Flow Rate for the First Consumer (Blue Line), after the Connection of the ACU on it

On the figure, you can observe the way of a heat carrier flow rate change among the first consumer, after the installation of ACU on it. The initial flow rate was
$12.52 \mathrm{t} / \mathrm{h}$ after the introduction of ACU, the automatic balancing valve brought the flow rate to the standard 
value and the flow rate was $8.2 \mathrm{t} / \mathrm{h}$, which practically coincides with the calculated value $(8.17 \mathrm{t} / \mathrm{h})$.
The initial performance of the heat network for the 38th micro district, the results of calculations and stand experiments are summarized in Table 1.

Table 1 Results of Calculations

\begin{tabular}{|l|l|l|l|l|}
\hline Input unit address & Indicator & With elevator units & $\begin{array}{l}\text { At the } \\
\text { introduction of } \\
\text { ACU } \\
\text { (Estimated } \\
\text { value) }\end{array}$ & $\begin{array}{l}\text { At the introduction } \\
\text { of ACU } \\
\text { (Laboratory } \\
\text { experiment) }\end{array}$ \\
\hline Amirkhana street, 2 & $\begin{array}{l}\text { Net water flow per } \\
\text { house, t/h }\end{array}$ & 12,52 & 8,17 & 8,2 \\
\hline Amirkhana street 4a & $\begin{array}{l}\text { Net water flow per } \\
\text { house, t/h }\end{array}$ & 7,8 & 5,05 & 5 \\
\hline $\begin{array}{l}\text { Amirkhana street 10, } \\
\text { bldg. 2 }\end{array}$ & $\begin{array}{l}\text { Net water flow per } \\
\text { house, t/h }\end{array}$ & 8,415 & 6,5 & 6,5 \\
\hline $\begin{array}{l}\text { Amirkhana street 2a } \\
\text { het water flow per } \\
\text { house, t/h }\end{array}$ & 10,79 & 8,29 & 8,3 \\
\hline $\begin{array}{l}\text { Yamasheva street, 74 } \\
\text { house, t/h }\end{array}$ & $\begin{array}{l}\text { Net water flow per } \\
\text { house, t/h }\end{array}$ & 12,36 & 9,55 & 9,5 \\
\hline $\begin{array}{l}\text { Yamasheva street, 76, } \\
\text { unit 2 }\end{array}$ & \begin{tabular}{l} 
Net \\
\hline
\end{tabular} & 7,86 & 7,8 \\
\hline
\end{tabular}

\section{Estimation of Economic Effect for Consumers during the Installation of Automated Metering and Regulating Units for Thermal Energy}

According to expert estimates, the excess heat consumption by RF residential areas makes about 30$40 \%$ today. Simultaneously with an inefficient use of thermal energy, the tariffs increase every year. So, for example, in 2010-2015 the growth of the tariff for thermal energy was $36.1 \%$ in the city of Kazan.

The economy of heat energy (20-30\%) in heat supply systems can be achieved due to the automatic regulation of heat consumption. The automation tasks can be implemented most completely and effectively using individual heat points (IHP) of buildings with the ability to regulate heat consumption at a consumer's request, depending on the temperature of outside air, a facility purpose, etc.

Previously, we published the results of studies that showed that with the transfer from CHP to IHP, the actual reduction of heat load for the heating of residential apartment buildings makes $33.5 \%$ on the average [7,8].

Let's estimate the economy of thermal energy as the result of accounting unit and automatic regulation installation by a consumer directly, using the example of a residential multi-apartment building located according to the following address: Kazan, Amirkhana str. $2 \mathrm{a}$.

The heat tariff (2015) for the population of Kazan is the following one: 1380.43 rubles/Gcal including VAT. An actual consumption of heat energy for heating during the heating period of 2014 amounted to 1144.3 Gcal or 1579.6 thousand rubles in value terms of 2014 including VAT.

According to the data presented in Table 2, the savings of thermal energy makes $20 \%$ of total consumption as the result of heat energy consumption regulation for heating using ACU, based on the demand and depending on the outside air temperature [9].

Table № 2 Expert estimation of thermal energy savings

\begin{tabular}{|l|l|l|}
\hline Stages of events & Amount of heat, Gcal & $\begin{array}{l}\text { Thermal energy } \\
\text { saving, } \%\end{array}$ \\
\hline Actual consumption of thermal energy & 1144.3 & - \\
\hline Thermal energy saving at ACU installation with weather control & 228.9 & $20,0 \%$ \\
\hline
\end{tabular}


The calculation approach is based on the comparison of the actual and the project (standard) heat consumption.

The determination of energy saving potential for heat energy on heating needs is based on the calculation of the weighted average value of thermal energy savings in two approaches described above. The results of the calculation are presented in Table No. 3.

Table №3 Estimation of thermal energy total savings in the heating system

\begin{tabular}{|l|l|l|l|}
\hline \multicolumn{1}{|c|}{ Indicator } & Measurement unit & \multicolumn{1}{c|}{ Expert estimation } & Calculation method \\
\hline \multirow{2}{*}{ Actual consumption of thermal energy } & & 1144.3 \\
\cline { 3 - 4 } Thermal energy saving & Gcal & 228.9 & 274.6 \\
\hline \multirow{2}{*}{ Weighted average thermal energy savings } & Gcal & thous.rub. & 347,52 \\
\cline { 2 - 4 } & $\%$ & $22 \%$ & 251,75 \\
\hline
\end{tabular}

\section{Discussion}

The conducted experiments showed that the introduction of ACU into a heat supply system allows to perform a more qualitative regulation of thermal energy distribution, prevents the over-flow of a heat carrier on the initial consumers and its shortage on the final ones.

\section{Conclusions}

An annual expected effect from the installation of metering units and automatic control can amount to $22 \%$ of the consumed thermal energy.

In monetary terms, according to the tariff for heat energy in 2015 the reduction of heat consumption will allow the apartment owners to reduce the cost of services provided to the amount of about 347.52 thousand rubles per year, including VAT.

In general, the effect from the implementation of ACU project is in the significant reduction of a building heat consumption and, accordingly, in the reduction of payment on consumed energy resources.

The achievement of this value of thermal energy saving is possible only with a proper equipment operation, periodic monitoring of its operation and provided that the upgraded buildings have a sufficient level of heat protection $[10,11]$.

\section{Summary}

The modern systems of heat supply are complex technical objects, during the management of which it is necessary to solve the issues of consumer provision with the required parameters of a heat carrier, associated with the establishment of preset pressures, the distribution of flows, and so on.
Due to the automated heat energy supply control unit (ACU) installed in a basement of a house, residents can save from 20 to 30 percent of heat, depending on the technical condition of a house.

The introduction of ACU reduces the monthly payments of residents of both multi-family and private households significantly. The equipment allows you to monitor the fluctuations of the outside air temperature and controls the amount and the temperature of a heat carrier supplied to a house.

Heat suppliers are forced to supply more energy into a house than necessary, since boiler equipment does not allow them to react quickly to the changes of outside air temperature. In order to reduce the temperature in the apartments, many open windows, thereby heating streets at their own expense and at the expense of their neighbors. The consequences of such actions are reflected in heating bills, which are overvalued by about 30 percent.

The solution of more complex problems, such as the prediction of a system behavior with the control actions on the multi-ring heat supply system of the city under different external conditions, for which several heat sources work simultaneously, requires the implementation of a software tool for the electronic modeling of heat network operating modes.

The results of our research showed that existing software packages created to model the operation of heat supply systems allow us to calculate the set modes, missing the dynamics of a system. In this case, there is a need to verify the results obtained on physical models (laboratory stands, experimental units).

The obtained results can be aimed at the increase of energy-saving measure effects and are used to optimize 
the operation of a heat supply system, powered simultaneously from several sources of thermal energy operating within a large area of the city.

\section{Acknowledgements}

The work is performed according to the Russian Government Program of Competitive Growth of Kazan Federal University.

\section{References}

[1] Zvonareva Yu.N., Vankov Yu.V. Energy saving in heat supply systems of large municipal associations, powered from several heat sources // Proceedings of Tomsk Polytechnic University, 2015, V.326, No. 11, No. 26, pp. 7582.

[2] Zvonareva Yu.N., Vankov Yu.V., Nazarychev S.A. Modeling of heat network operation modes for the purpose of thermal energy efficient use. Proceedings of the 16th International Symposium "Energy Resource Efficiency and Energy Saving", 2016. pp. 209-212.

[3] Vankov, Yu. V., Ziganshin, Sh. G.,Izmailova, E. V.,Politova, T. O. Methods check the piping using a neural network(2015) IOP Conference Series: Materials Science and Engineering, 86 (1), no. 012037.

[4] Allen B., Savard-Goguen M., Gosselin L. Optimizing heat exchanger networks with genetic algorithms for designing each heat exchanger including condensers// Applied Thermal Engineering. 2009.

[5] DINV 4701-10:2002. Belblatt 1. Energetische Bevertung heiz-undraum-lufttechnischer. Anlagen. Heizung, Trinkwassererewarmung, Luftung.
[6] Petitjean R. Total hydronic balancing: A handbook for design and troubleshooting of hydronic HVAC systems.- Gothenburg: TA $\mathrm{AB}, 1994$. $-530 \mathrm{p}$.

[7] Zvonareva Yu.N., Vankov Yu.V. The evaluation of energy efficiency and the changes in the performance of a heat supply system, taking into account the phased introduction of automatic metering and thermal energy unit regulation for consumers, VIIth International Scientific and Practical Conference "The 21st Century: Fundamental Science and Technologies". - North Charleston, SC, USA: CreateSpace, 2015. - Volume 2, pp. 131-133.

[8] Zvonareva Yu.N., Vankov Yu.V., Polenov L.A., Pavlov L.A. The influence of stage-by-stage introduction of AITP on hydraulic stability of the system as a whole // Energy-resource efficiency and energy saving in the Republic of Tatarstan: works / under gen. ed. by Martynov E.V. // XVth International Symposium, Kazan, 1-3 of April, 2015. - Kazan: Publishing house IE Shaihutdinov A.I., 2015.-524 pp. 77-79.

[9] ASHRAE. Fundamentals of heating systems. Atlanta, 1988.

[10] Zvonareva Yu.N., Vankov Yu.V., Nazarychev S.A. Estimation of the economic effect for consumers during the installation of automated metering and regulating units for thermal energy // Engineering Bulletin of the Don, 2015, №4 URL: don.ru/ru/magazine/archive/n4y2015/3315.

[11] Saifullin, E.R., Nazarychev, S.A., Malahov, A.O., Larionov, V.M., Iovleva, O.V. The heat effect of combustion process depending on fuel composition fluctuations (2017) Journal of Physics: Conference Series, 789 (1), № 012045. 